\title{
Lipid and Moisture Content of Commercial Reduced-Fat Deep-Fried Potatoes Compared to Advertised Claim
}

\author{
Sherri N. Stastny ${ }^{1}$, Jill F. Keith ${ }^{1} \&$ Cliff Hall III ${ }^{2}$ \\ ${ }^{1}$ Health, Nutrition and Exercise Sciences, North Dakota State University, Fargo, ND, USA \\ ${ }^{2}$ Cereal Science, North Dakota State University, Fargo, ND, USA \\ Correspondence: Sherri N. Stastny, Health, Nutrition and Exercise Sciences, North Dakota State University, \\ Fargo, ND, 58103, USA. Tel: 1-701-231-7479. E-mail: sherri.stastny@ndsu.edu
}

Received: March 19, 2014 Accepted: June 5, 2014 Online Published: June 21, 2014

doi:10.5539/jfr.v3n5p45 URL: http://dx.doi.org/10.5539/jfr.v3n5p45

\begin{abstract}
Deep-fat frying is a common food preparation method for potatoes in the foodservice industry. Deep-fried potatoes (French fries) are top-sellers at fast food establishments such as Burger King ${ }^{\circledR}$ and McDonald's ${ }^{\mathrm{TM}}$. Intake of calorie-dense foods without increasing physical activity can lead to unhealthy weight gain. Burger King ${ }^{\circledR}$ currently offers a healthier deep-fried potato option (Satisfries ${ }^{\mathrm{TM}}$ ) claiming $40 \%$ less fat and $30 \%$ less calories than McDonald's ${ }^{\mathrm{TM}}$ French fries. The fat content of McDonald's ${ }^{\mathrm{TM}}$ and Burger King ${ }^{\circledR}$ regular deep-fried potatoes and Satisfries ${ }^{\mathrm{TM}}$ were compared in this study to evaluate the accuracy of the health claim. Results indicated the Burger King ${ }^{\circledR}$ Satisfries ${ }^{\mathrm{TM}}$ averaged 36\% less fat than McDonald's ${ }^{\mathrm{TM}}$ and $22 \%$ less fat than regular Burger King ${ }^{\circledR}$ French fries. These results fall within $4 \%$ of the health claim advertised by Burger King ${ }^{\circledR}$.
\end{abstract}

Keywords: French fries, Satisfries ${ }^{\mathrm{TM}}$, fat content, fast food, Burger King ${ }^{\circledR}$, McDonald's $^{\mathrm{TM}}$

\section{Introduction}

Foods consumed away from home account for over half of American's food dollars (US Department of Agriculture [USDA], 2013). Of the money spent on food (at home and away from home) in the United States, the restaurant industry share is 47\% (National Restaurant Association, 2013). Foods eaten away from home, such as deep-fried potatoes, tend to be higher in energy and fat (Bezerra, Curioni, \& Sichieri, 2012). Deep-fried potatoes (i.e. French fries) are a commonly consumed food product when eating away from home and are one of the most popular potato products in the world (Kita \& Lisinska, 2005; Mehta \& Swinburn, 2001). French Fries are among the top selling items at McDonald's ${ }^{\text {TM }}$ (Anonymous, 2011).

Increased consumption of calorie-dense foods, such as those that are coated and deep-fried, without an equal increase in physical activity, leads to undesirable weight gain. Worldwide, obesity and overweight doubled between 1980 and 2008, including low- and middle-income countries joining the highest-income countries with this growing problem. National data indicates more than one-third $(35.7 \%)$ of American adults and approximately $17.0 \%$ of children and adolescents are obese (Centers for Disease Control and Prevention [CDC], 2011a, 2011b). Obesity contributes to the leading causes of preventable death including heart disease, type 2 diabetes, stroke, and certain forms of cancer (CDC, 2011b). At least 2.8 million people die each year as a result of being overweight or obese. The World Health Organization recommends a limit to total fat intake to help prevent obesity (WHO, 2013).

Healthier cooking techniques or the development of new products for deep-fat frying that absorb or contain less fat while still exhibiting golden color, crispiness desired in fried foods have been attempted. Sensory qualities of appearance, aroma, and taste upon first bite and with chewing, and crispness have been reported to be significantly higher in deep-fried fish compared to oven-baked breaded fish (Perez-Palacios, Casal, Petisca, \& Ferreira, 2013). Fat content of cooked coated tuna and ham was lower when baked compared to deep fat fried (Miranda et al., 2010). Some researchers have added fiber to deep-fried bread products to reduce fat uptake (Yadav \& Rajan, 2012). Others have coated food pieces with hydrocolloids, which are starchy gum coatings (Tavera-Quiroz, Urriza, Pinotti, \& Bertola, 2011). Deep-fried potatoes have been dipped in sugar or salt solutions, coated with cellulose derivatives, or vacuum fried in an attempt to lower the fat and energy contribution (Bingol, Zhang, Pan, \& McHugh, 2012). Components of breading on shrimp and chicken products as well as 
post-breading dips have been manipulated to facilitate changes in fat uptake (Nasiri, Mohebbi, Yazdi, \& Khodaparast, 2012; Mah \& Brannan, 2008).

At least one fast food chain is attempting to reach consumers that desire fried foods for their sensory and satisfaction attributes while showing a disinclination for fried food's added calories and fat. Burger King® (BK) is reported to have a "better for you" optionin several categories including entrees (crispy chicken strip), beverages (frappe) and recently with their Satisfries ${ }^{\mathrm{TM}}$, as they try to market to women, children, and families (Nassauer, 2013). The new deep-fried coated potato (i.e. French fry) product, under development for over 10 years, is reported to have "great taste, less fat" (Anonymous, 2013a). According to company literature, the product is lightly battered, par-fried, then frozen for distribution (Anonymous, 2013a). Advertising visible in sampled BK restaurants as well as on the BK website contain the claim that the crinkle-cut Satisfries ${ }^{\mathrm{TM}}$ have $40 \%$ less fat (11.2 g vs. $6.3 \mathrm{~g}$ ) and $30 \%$ fewer calories (226.8 calories vs. 150.5 calories) than McDonald's ${ }^{\mathrm{TM}}$ deep-fried potatoes for a $70 \mathrm{~g}$ "small" serving.

The aim of this study is to evaluate the fat content of McDonald's ${ }^{\mathrm{TM}}$ and BK regular deep-fried potatoes and Satisfries ${ }^{\mathrm{TM}}$ to determine the difference in fat content and whether the restaurant chain accurately reflects the health claims of the fries. In order to check the accuracy of the health claim, the portion sizes of purchased samples were compared to the portion size in the advertised claim.

\section{Materials and Methods}

\subsection{Samples}

Samples were obtained from 3 different BK and McDonald's ${ }^{\mathrm{TM}}$ locations within a two-state area on 2 different days. A sample of regular fries and/or Satisfries ${ }^{\mathrm{TM}}$ was obtained from each of the 3 different BK and McDonald's ${ }^{\mathrm{TM}}$ locations during the dinner hour (3:00 p.m. to 7:00 p.m.), all in the "small" portion size. Samples were cooled in original-purchase paper bags, stored in individual zip top bags, and then frozen until needed. Restaurants were not informed about the experiment.

\subsection{Chemical Analysis}

Samples were freeze-dried (Labconco, Kansas City, MO, USA) and milled into a powder $(<149 \mu \mathrm{m})$ using a laboratory mill (Ika, Wilmington, NC, USA). Moisture content among the samples was determined using freeze-drying and weight loss difference. Following freeze-drying, $3 \mathrm{~g}$ of each sample were placed in Soxhlet extractor overnight $(16 \mathrm{~h})$. The lipid content was determined gravimetrically by weighing the oil or fat obtained after evaporating the solvent (AOCS, 2009). The fat content obtained was the average from 12 oil extractions for each sample. The reported fat contents are on an "as is" basis.

\subsection{Statistical Analysis}

A one-way ANOVA was computed to compare moisture content across 3 samples of French fries (BK Regular, BK Satisfries ${ }^{\mathrm{TM}}$, and McDonald's ${ }^{\mathrm{TM}}$ regular). An additional one-way ANOVA was computed to compare fat content across the 3 samples of French fries. Statistical analyses were carried out using SPSS 21.0 (IBM SPSS Statistics for Windows, Version 21.0. Armonk, NY: IBM Corp, 2012). The statistical significance was defined as $p<0.05$.

\section{Results and Discussion}

\subsection{Sample Sizes}

Nutrition information health claims are matched to a specific portion size, so it is important to first determine if portion sizes were as intended. Each sample was weighed after freezing. According to the restaurant websites, a small serving of McDonald's ${ }^{\mathrm{TM}}$ French fries weighs $71 \mathrm{~g}$ (Anonymous, 2013b); a small serving of BK regular French fries weighs $70 \mathrm{~g}$ and Satisfries ${ }^{\mathrm{TM}} 70 \mathrm{~g}$ (Anonymous, 2013c). The mean weight of the samples procured for the current study ranged from 50 to $70 \mathrm{~g}$ (mean $60 \mathrm{~g}$ ) for McDonald's ${ }^{\mathrm{TM}}$; 61 to $66 \mathrm{~g}$ (mean $64 \mathrm{~g}$ ) for regular $\mathrm{BK}$; and 66 to $76 \mathrm{~g}$ (mean $71 \mathrm{~g}$ ) for Satisfries ${ }^{\mathrm{TM}}$. Means compared to advertised portion sizes were $11 \mathrm{~g}$ smaller, 6 $\mathrm{g}$ less, and 13g larger for McDonald's ${ }^{\mathrm{TM}}$, regular BK, and for Satisfries ${ }^{\mathrm{TM}}$, respectively.

\subsection{Moisture and Fat Content}

For all samples, moisture content ranged from 25.3 to $55.1 \%$ as illustrated in Table 1 . 
Table 1. Mean moisture and fat content (\%) and fat grams per serving for three commercial French fry products

\begin{tabular}{cccc}
\hline & Moisture content $(\%)^{*}$ & Fat content $(\%)^{*}$ & Fat Content $(\mathrm{g})$ in $70 \mathrm{~g}$ serving \\
\hline McDonald's $^{\mathrm{TM}}$ & $29.7 \pm 2.94^{\mathrm{a}}$ & $20.1 \pm 0.70^{\mathrm{a}}$ & 14.1 \\
Regular BK $^{\mathrm{B}}$ & $36.2 \pm 3.92^{\mathrm{b}}$ & $16.6 \pm 0.51^{\mathrm{a}}$ & 11.6 \\
BK Satisfries $^{\mathrm{TM}}$ & $50.5 \pm 4.08^{\mathrm{c}}$ & $12.9 \pm 1.24^{\mathrm{b}}$ & 9.0 \\
\hline
\end{tabular}

Note. *Values with different letters within the columns are significantly different. $\mathrm{P}<0.05$.

Percent fat in original samples ranged from 11.1 to $22.3 \%$ percent. Moisture content was significantly higher in both the regular and Satisfries ${ }^{\mathrm{TM}}$ from BK compared to McDonald's ${ }^{\mathrm{TM}}$ samples $(F=69.78, p<0.01)$, with the highest moisture content present in BK Satisfries ${ }^{\mathrm{TM}}$. The fat content in the Satisfries ${ }^{\mathrm{TM}}$ was significantly lower than the BK regular and McDonald's ${ }^{\mathrm{TM}}$ French fries $(F=26.05, p<0.01)$. The higher moisture content likely contributed to the lower fat content for both BK types of samples. The amount of oil absorbed by food is influenced by food surface area and moisture content of foods (Choe \& Min, 2007). In addition, thicker-cut fried potato products absorb less fat than thinner cuts (Mehta \& Swinburn, 2001). The BK Satisfries ${ }^{\mathrm{TM}}$ were visibly thicker, had a higher mean weight, and higher moisture content than the regular fries.

On average the Satisfries ${ }^{\mathrm{TM}}$ had $36 \%$ less fat than McDonald's ${ }^{\mathrm{TM}}$ and $22 \%$ less fat than the BK regular size French fries. The average fat content for a $70 \mathrm{~g}$ serving was $14.1,11.6$ and $9.0 \mathrm{~g}$ for McDonald's ${ }^{\mathrm{TM}}$ French fries, BK regular size French fries and Satisfries ${ }^{\mathrm{TM}}$, respectively (Table 1). All samples contained more fat than indicated in the advertising. The tested samples were within $4 \%$ of the claim. The differences in oil contents might be due to different preparations at the various chain locations. Furthermore, the larger Satisfries ${ }^{\mathrm{TM}}$ had a higher fat content standard deviation, thus indicating that the product also contributed to differences in fat content compared to the claim. It is likely that the information in the advertised claim was done in a more controlled environment and therefore produced slightly different values than those obtained in this study. However, the advertised lower fat in Satisfries ${ }^{\mathrm{TM}}$ is true.

\section{Conclusions}

Recommendations for consumers to eat at home and discontinue consumption of foods from restaurants are unrealistic and impractical because of the significant amount of food dollars spent on foods eaten away from home. There are 12,300 BK restaurants worldwide, serving more than 11 million consumers daily (Vu, Bo, Brooks, Cheng, \& Tsang, 2013). BK currently has 6.5 million likes on social media Facebook and has the potential to drive a shift in consumer habits (Lukovitz, 2013). It is important to note nutrition claims and menu offerings from globally impactful restaurants as information and choices may have an impact on the overweight and obese. Assisting consumers in making healthful choices offered by dining establishments may be a more realistic alternative for improving consumer dietary habits.

The Burger King ${ }^{\circledR}$ Satisfries ${ }^{\mathrm{TM}}$ are a healthier alternative to regular French fries at BK and McDonald's ${ }^{\mathrm{TM}}$ as they have lower fat content and thus less calories. It would follow that if one wants to limit dietary fat content, the BK Satisfries ${ }^{\mathrm{TM}}$ may be a prudent option but that portion sizes may vary from location to location. However, deep-fried food products should still be consumed in moderation as they are a calorie-dense food and may contribute to undesirable weight gain and poor health outcomes.

\section{Acknowledgement}

The authors wish to thank Mary Niehaus for her kind assistance with chemical analysis.

\section{References}

AOCS. (2009). Official Methods and Practices of the AOCS. Urbana, IL: AOCS Press.

Anonymous. (2011). McDonald's ${ }^{\mathrm{TM}}$ Restaurant Annual report 2011. Retrieved from http://www.aboutmcdonalds.com/content/dam/AboutMcDonalds/Investors/Investors\%202012/2011\%20An nual\%20Report\%20Final.pdf

Anonymous. (2013a). McCain foods product booth. Food and Nutrition Conference and Expo (FNCE) of the Academy of Nutrition and Dietetics Annual Conference. Houston, TX.

Anonymous. $\quad$ (2013b). McDonald's ${ }^{\text {TM }} \quad$ Restaurant. $\quad$ Retrieved from http://www.mcdonalds.com/us/en/food/product_nutrition.snackssides.120.Small-French-Fries.html 
Anonymous. (2013c). Burger King ${ }^{\circledR}$ Restaurant. Retrieved from http://www.bk.com/en/us/satisfries/htm

Bezerra, I., Curioni, C., \& Sichieri, R. (2012). Association between eating out of home and body weight. Nutrition Reviews, 70, 65-79. http://dx.doi.org/10.1111/j.1753-4887.2011.00459.x

Bingol, G., Zhang, A., Pan, Z., \& McHugh, T. (2012). Producing lower-calorie deep fat fried French fries using infrared dry-blanching as pretreatment. Food Chemistry, 132, 686-692. http://dx.doi.org/10.1016/j.foodchem.2011.10.055

Center for Disease Control (CDC). (2011a). Childhood obesity rates. Retrieved from http://www.cdc.gov/obesity/data/childhood.html

CDC. (2011b). Adult obesity facts. Retrieved from http://www.cdc.gov/obesity/data/adult.html

Choe, E., \& Min, D. B. (2007). Chemistry of deep-fat frying oils. Journal of Food Science, 72(5), R77-R86. http://dx.doi.org/10.1111/j.1750-3841.2007.00352.x

Kita, A., \& Lisinska, G. (2005). The influence of oil type and frying temperatures on the texture and oil content of French fries. Journal of Science Food and Agriculture, 85, 2600-2604. http://dx.doi.org/10.1002/jsfa.2319

Lukovitz, K. (2013). BK sees perception gains after 'Satisfries' ${ }^{\mathrm{TM}}$ ' launch. Retrieved from http://www.mediapost.com/publications/article/210634/bk-sees-perception-gains-after-Satisfries ${ }^{\text {TM}-l a u n c h . h ~}$ tml

Mah, E., \& Brannan, R. G. (2008). Reduction of oil absorption in deep-fried, battered, and breaded chicken patties using whey protein isolate as a postbreading dip: effect on flavor, color, and texture. Journal of Food Science, 74, S9-S16. http://dx.doi.org/ 10.1111/j.1750-3841.2008.00973.x

Mehta, U., \& Swinburn, B. (2001). A review of factors affecting fat absorption in hot chips. Critical Reviews Food Science and Nutrition, 41, 133-154. http://dx.doi.org/10.1080/20014091091788

Miranda, J. M., Martinez, B., Perez, B., Anton, X., Vazquez, B. I., Fente, C. A., ... Cepeda, A. (2010). The effects of industrial pre-frying and domestic cooking methods on the nutritional compositions and fatty acid profiles of two different frozen breaded foods. Food Science Technology, 43, 1271-1276. http://dx.doi.org/10.1016/j.lwt.2010.03.013

Nassauer, S. (2013, September 23). BK tries new French fries. Wall Street Journal. Retrieved from http://online.wsj.com/news/articles/SB10001424052702304713704579093600703446782

Nasiri, F. D., Mohebbi, M., Yazdi, F. T., \& Khodaparast, M. H. H. (2012). Effects of soy and corn flour addition on batter rheology and quality of deep fat-fried shrimp nuggets. Food Bioprocess Technology, 5, 1238-1245. http://dx.doi.org/ 10.1007/s11947-010-0423-4

National Restaurant Association. (2013). Facts at a glance. Retrieved from http://www.restaurant.org/News-Research/Research/Facts-at-a-Glance

Perez-Palacios, T., Casal, S., Petisca, C., \& Ferreira, I. (2013). Nutritional and sensory characteristics of bread-coated hake fillets as affected by cooking conditions. Journal of Food Quality, 35, 375-384. http://dx.doi.org/ 10.1111/jfq.12057

Tavera-Quiroz, M. J., Urriza, M., Pinotti, A., \& Bertola, A. (2012). Plasticized methylcellulose coating for reducing oil uptake in potato chips. Journal of Science Food and Agriculture, 92, 1346-1353. http://dx.doi.org/10.1002/jsfa.4704

United States Department of Agriculture (USDA). (2013). Food Expenditures 2013. Retrieved from http://www.ers.usda.gov/data-products/food-expenditures.aspx

Vu, A., Bo, D., Brooks, J., Cheng, V., \& Tsang, M. (2013). Burger King ${ }^{\circledR}$ : Changing or imitating? Analysis of BK's re-strategy (Master's Thesis). Santa Clara University, Santa Clara, CA. Abstract retrieved from http://www.grin.com/en/e-book/202436/burger-king-changing-or-imitating

World Health Organization. (2013). 10 facts on obesity. Retrieved from http://www.who.int/features/factfiles/obesity/en/

Yadav, D. N., \& Rajan, R. (2012). Fibres as an additive for oil reduction in deep fat fried poori. Journal of Food Science and Technology, 49, 767-773. http://dx.doi.org/ 10.1007/s13197-010-0218-7

\section{Copyrights}

Copyright for this article is retained by the author(s), with first publication rights granted to the journal.

This is an open-access article distributed under the terms and conditions of the Creative Commons Attribution license (http://creativecommons.org/licenses/by/3.0/). 